\title{
Pengujian Black Box pada Aplikasi Sistem Informasi Pengelolaan Masjid Menggunakan Teknik Equivalence Partitions
}

\author{
Hendri $^{1}$, Jimmy Walter Hasiholan Manurung ${ }^{2}$, Rifqi Audi Ferian ${ }^{3}$, Wahyu Faharrudin \\ Hanaatmoko ${ }^{4}$, Yulianti Yulianti ${ }^{5}$
}

Teknik Informatika, Universitas Pamulang, Tangerang Selatan, Banten, Indonesia

e-mail: ${ }^{1}$ hendri78ten@ gmail.com, ${ }^{2}$ reynover@gmail.com, ${ }^{3}$ rifqiaudi48@ gmail.com, 4faharudinw@gmail.com, ${ }^{5}$ yulianti@unpam.ac.id

Submitted Date: March 22 $2^{\text {nd }}, 2020$

Revised Date: April 06 ${ }^{\text {th }}, 2020$
Reviewed Date: April 05 ${ }^{\text {th }}, 2020$

Accepted Date: April 29 $9^{\text {th }}, 2020$

\begin{abstract}
Black-box testing is very important because this technique is able to identify errors in functions, interfaces, data models, and access to external data sources. In implementation problems often arise when testers are never sure whether the software being tested has actually passed the test. This happens because there may be several execution paths that have never been tested. Testers must make every possible input data combination for testing. The selection of input data to find errors is a problem for testers because it has a high probability, so the test case design can automatically become a solution. In this implementation the application to be tested using black-box testing is the Mosque Management Information System. The Mosque Management application will be tested using black box testing where the test is only intended to see if the program matches the function desired by the program without knowing the program code used. To produce test case designs automatically in black box method software testing with equality partition technique. Equivalence Partitions technique is a test based on entering data on each form in the mosque management information system, each menu will be tested and grouped according to function whether it is valid or not.
\end{abstract}

Keywords: Application; Testing, Black Box; Equality Partition; Mosque Management System

\section{Abstract}

Pengujian black-box sangat penting karena teknik tersebut mampu mengidentifikasi kesalahan dalam fungsi, antar muka, model data, dan akses kesumber data eksternal. Dalam pelaksanaan sering timbul masalah penguji tidak pernah yakin apakah perangkat lunak yang diuji telah benar-benar lolos dalam pengujian. Hal ini terjadi karena kemungkinan masih ada beberapa jalur eksekusi yang belum pernah teruji. Penguji seharusnya membuat setiap kemungkinan kombinasi data masukan untuk pengujian. Pemilihan data masukan untuk menemukan kesalahan menjadi masalah bagi penguji karena memiliki probabilitas yang tinggi, sehingga desain test case secara otomatis dapat menjadi solusi. Pada implementasi ini aplikasi yang akan di uji menggunakan black-box testing adalah sebuah Sistem Informasi Pengelolaan Masjid. Aplikasi Pengelolaan Masjid tersebut akan diuji menggunakan black-box testing di mana pengujian ini hanya bertujuan untuk melihat program tersebut apakah sesuai dengan fungsi yang diinginkan program tersebut tanpa mengetahui kode program yang dipakai. Untuk menghasilkan desain test case secara otomatis dalam pengujian perangkat lunak metode black-box dengan teknik equivalence partitioning. Teknik Equivalence Partitions adalah pengujian didasarkan masukkan data pada setiap form yang ada pada sistem informasi pengelolaan masjid, setiap menu akan dilakukan pengujian dan dikelompokkan berdasarkan fungsinya baik itu bernilai valid ataupun tidak valid.

Keyword: Aplikasi; Pengujian; Black Box; Equivalence Partitions; Sistem Pengelolaan Masjid 


\section{Pendahuluan}

Pengujian pada sebuah program penting untuk dilakukan guna memeriksa semua kesalahan yang ada pada program tersebut agar tidak menimbulkan hal-hal yang merugikan pada saat digunakan (Ningrum, Suherman, Aryanti, Prasetya, \& Saifudin, 2019). Hal yang perlu diperhatikan dalam melakukan pengujian adalah pengujian harusnya dapat mendapatkan kesalahan yang mungkin sebelumnya tidak terdeteksi dan dikatakan berhasil pengujian tersebut apabila dapat memperbaiki kesalahan tersebut sehingga kualitas software akan lebih baik. Dalam pengujian hal yang perlu diperhatikan adalah perancangan yang baik agar dapat dengan mudah menemukan kesalahan pada saat pengujian agar dapat diperbaiki dengan cepat sehingga dapat menghemat waktu dalam pengujian.

Pada penelitian ini sistem yang akan dikerjakan adalah sistem pengelolaan masjid yang digunakan untuk memudahkan dalam mencari informasi seputar Masjid At-Taqwa. Sistem Pengelolaan Masjid tersebut menggunakan sebuah metode yaitu metode hasil bobot terbaik (Mukhayaroh, 2016).

Berdasarkan dari observasi yang dilakukan dalam menentukan sales terbaik masih menggunakan cara yang manual yang cenderung tidak akurat khususnya bagi perusahaan. Dari permasalahan yang ada dibutuhkan sebuah aplikasi penunjang keputusan pemilihan sales terbaik yang diharapkan dengan adanya aplikasi tersebut akan dapat memberikan keuntungan bagi perusahaan (Sasmito, 2017).

Program yang akan dibuat pada pengkajian ini adalah program sistem seleksi sales terbaik adalah Blackbox Testing, di mana pengujian bertujuan melihat program tersebut sama dengan tugas program tersebut tanpa mengetahui kode program yang dipakai. Tahapan pertama pada pengujian dengan menggunakan Blackbox Testing adalah mengidentifikasi masukan lalu diuji agar kita mengetahui letak kesalahannya. Pengujian menggunakan Blackbox Testing merupakan sebuah pengujian yang digunakan untuk melengkapi pengujian sebelumnya yaitu Whitebox Testing agar aplikasi yang kita buat memiliki kualitas yang baik serta waktu yang digunakan akan lebih efektif, sehingga dapat menguntungkan bagi perusahaan (Mustaqbal, Firdaus, \& Rahmadi, 2015).

Ada beberapa cara dalam menguji Black Box Testing salah satunya adalah mengunakan teknik Equivalence Partitions. Equivalence
Partitions merupakan sebuah pengujian berdasarkan masukkan data pada setiap form yang ada pada sistem seleksi sales terbaik, setiap menu masukan akan dilakukan pengujian dan dikelompokkan berdasarkan fungsinya baik itu bernilai valid ataupun tidak valid (Hidayat \& Muttaqin, 2018).

Dalam penelitian ini terdapat beberapa tahapan, di mana diawali dengan menentukan Test Case yang akan diuji, kemudian membaginya dengan beberapa partisi masukan dan keluaran. Hal ini dilakukan untuk mendapatkan dokumentasi pengujian (MZ, 2016).

\section{Metodologi}

Pengujian merupakan suatu proses pelaksanaan program yang bertujuan menemukan kesalahan dan memperbaikinya sehingga sistem dikatakan layak untuk digunakan (Nurudin, Jayanti, Saputro, Saputra, \& Yulianti, 2019). Pengujian pada sistem menggunakan metode Black Box, tujuannya untuk mengetahui bahwa bagian-bagian dalam sistem aplikasi telah benar menampilkan pesan-pesan kesalahan jika terjadi kesalahan dalam pemasukan data (Ferdinandus, Wowor, Lumenta, \& Rumagit, 2012). Black Box Testing sendiri merupakan pengujian yang dilakukan hanya mengamati hasil eksekusi melalui data uji dan memeriksa fungsional dari perangkat lunak (Krismadi, et al., 2019). Pengujian black box ini menitik beratkan pada fungsi sistem (Syaban \& Bunyamin, 2015).

Dalam tahap pengujian Equivalence Partitions pertama yang dilakukan adalah membuat rencana/rancangan test case berdasarkan fungsi yang ada dalam pengujian perangkat lunak.

Metode Blackbox Testing adalah sebuah metode yang dipakai untuk menguji sebuah software tanpa harus memperhatikan detail software. Pengujian ini hanya memeriksa nilai keluaran berdasarkan nilai masukan masingmasing. Tidak ada upaya untuk mengetahui kode program apa yang output pakai (Latif, 2015). Proses Black Box Testing dengan cara mencoba program yang telah dibuat dengan mencoba memasukkan data pada setiap formnya. Pengujian ini diperlukan untuk mengetahui program tersebut berjalan sesuai dengan yang dibutuhkan oleh perusahaan (Wahyudi, Utami, \& Arief, 2016).

Salah satu jenis pengujian Blackbox Testing adalah dengan menggunakan teknik Equivalence Partitioning (EP) yang penulis gunakan untuk menguji masukan serta membagi masukan kedalam 
kelompok-kelompok berdasarkan fungsinya. Sehingga didapatkan sebuah test case yang akurat (Aristoteles, Wardiyanto, \& Pratama, 2015). Dalam penelitian ini akan dilakukan beberapa tahapan. Pada tahapan pertama diawali dengan menentukan Test Case perangkat lunak yang akan diuji dengan metode Equivalence Partition kemudian menginisialisasi standar grade partition masukan dan keluaran. Hal ini dilakukan untuk mendapatkan dataset berupa dokumentasi pengujian dengan metode Equivalence Partitions dan nilai tingkat efektifitas metode Equivalence Partitions.
Kemudian membuat batasan pengujian Equivalence Partitions, setelah membuat batasan pengujian, langkah selanjutnya adalah membuat model pengujian dari skenario pengujian dan hasil yang diharapkan, dan yang terakhir melakukan pengujian berdasarkan model yang dirancang. Hal ini dilakukan untuk mendapatkan data berupa dokumentasi pengujian dengan metode Equivalence Partitions dan nilai tingkat efektifitas metode Equivalence Partitions (Jaya, Gumilang, Wati, Andersen, \& Desyani, 2019).

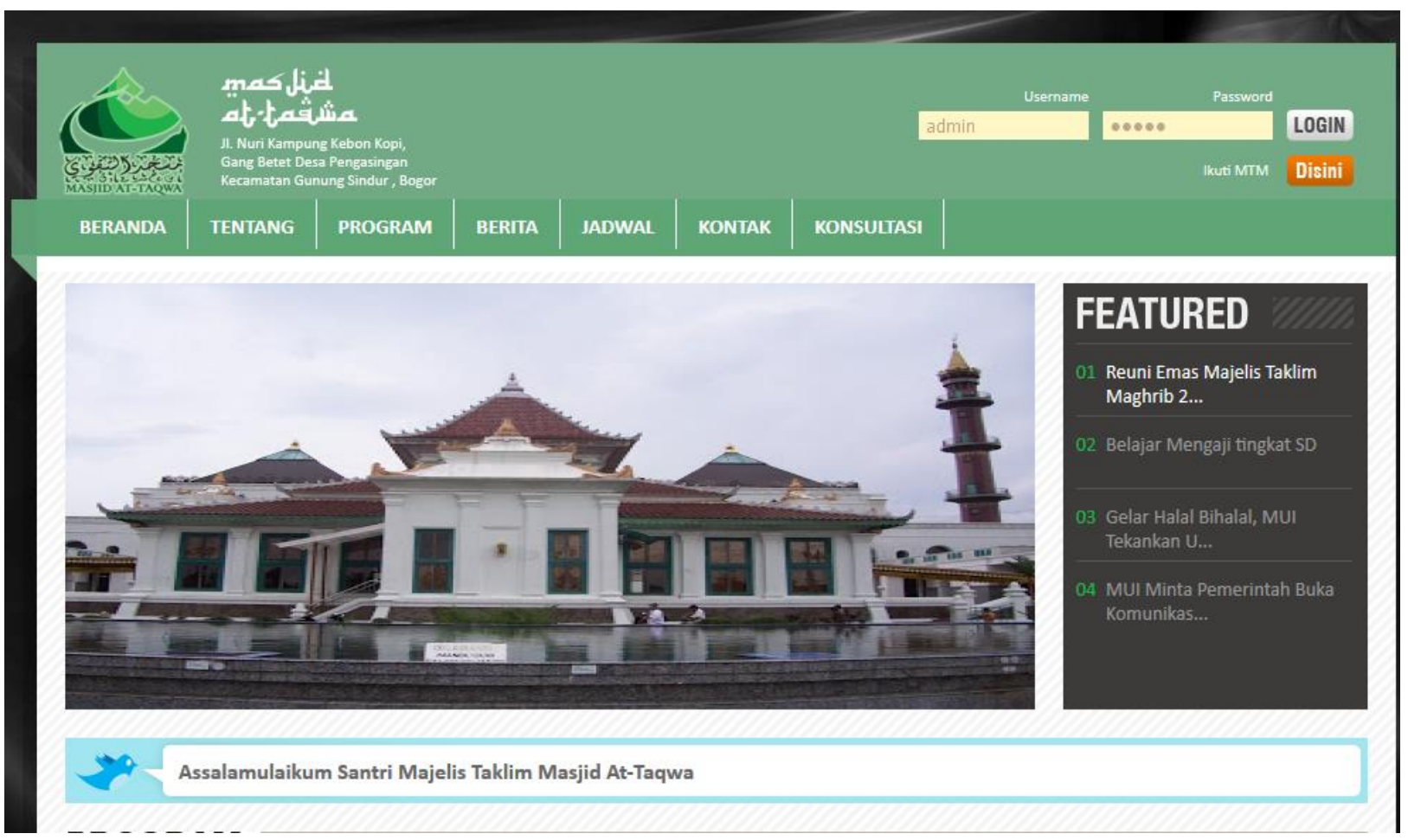

Gambar 1 Form Login

Berdasarkan form pada Gambar 1 terdapat beberapa rencana pengujian. Pada rencana pengujian E-mail data akan valid jika E-mail harus diisi dengan memasukkan kata (contohnya "rifqiaudi48@gmail.com") dengan password ("admin123"), setelah mengisi form maka Sistem menerima dan menampilkan pemberitahuan
("Success"), apabila jika password diisi dengan password yang salah contohnya ("123") saja maka sistem akan menolak dan menampilkan pemberitahuan ("Alamat E-mail dan password tidak cocok") dan begitu juga apabila mengosongkan E-mail dan password.

Tabel 1 Rancangan Test Case Form Login

\begin{tabular}{|c|c|c|}
\hline Id & Deskripsi pengujian & Hasil yang diharapkan \\
\hline A01 & $\begin{array}{l}\text { Mengisi } \quad \text { E-mail } \\
\text { "rifqiaudi48@gmail.com dan Password } \\
\text { dengan "admin123" lalu menekan tombol } \\
\text { "Login" }\end{array}$ & $\begin{array}{l}\text { Sistem menerima dan menampilkan } \\
\text { pemberitahuan "Success" Kemudian tampil } \\
\text { halaman beranda }\end{array}$ \\
\hline
\end{tabular}




\begin{tabular}{|l|lr|lrr|}
\hline A02 & $\begin{array}{l}\text { Mengisi } \\
\text { "ariefmaulana9898@gmail.com } \\
\text { Password dengan "123" lalu } \\
\text { tombol "Login" }\end{array}$ & $\begin{array}{r}\text { dengan } \\
\text { dan } \\
\text { menekan }\end{array}$ & $\begin{array}{l}\text { Sistem akan menolak dan menampilkan } \\
\text { pemberitahuan "Alamat E-mail dan Password } \\
\text { tidak cocok" }\end{array}$ \\
\hline A03 & $\begin{array}{l}\text { Mengkosongkan E-mail dan Password lalu } \\
\text { menekan tombol "Login" }\end{array}$ & $\begin{array}{l}\text { Sistem akan menolak dan menampilkan } \\
\text { "Alamat E-mail dan Password tidak cocok" }\end{array}$ \\
\hline
\end{tabular}

\section{$\begin{array}{llllll}\text { Home } & \text { Static Content } & \text { Dynamic Content } & \text { Setting } & \text { Profile } & \text { View Site }\end{array}$}

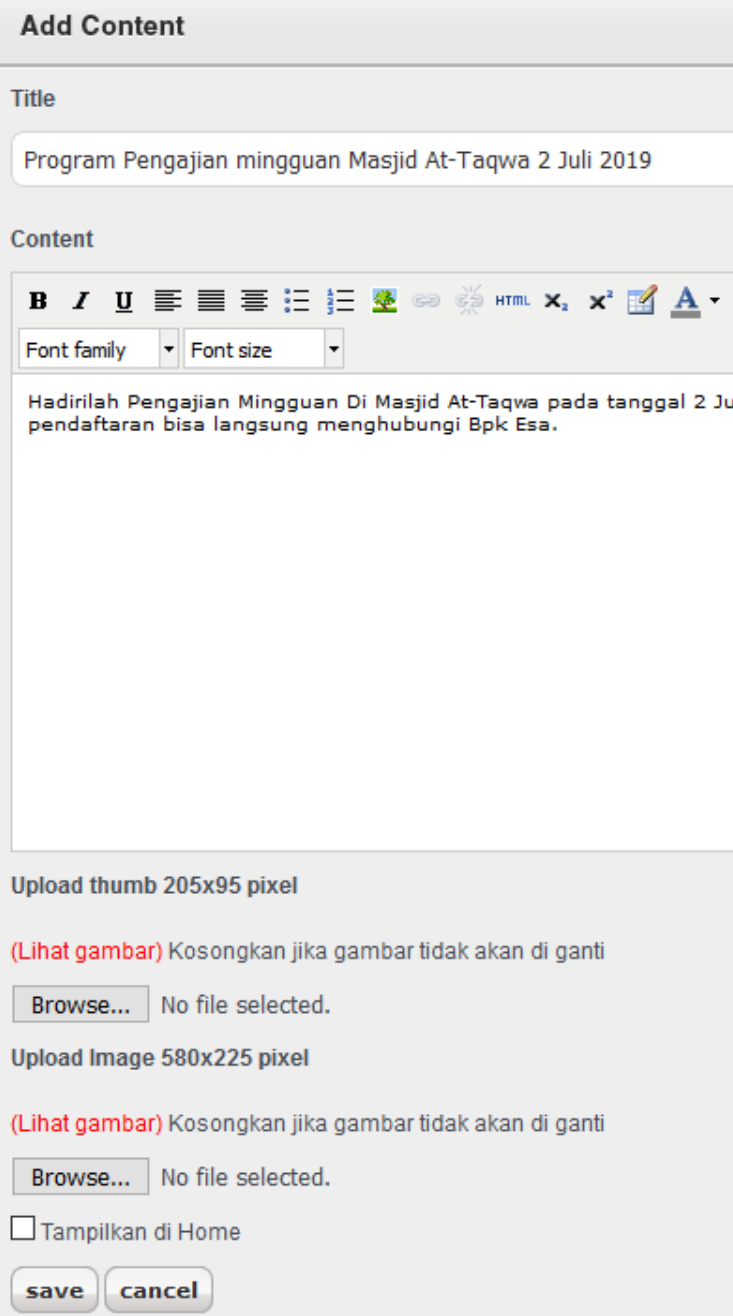

Gambar 2 Tampilan Form Data Program/Event

Pengujian berikutnya dilakukan pada form Data dengan memasukkan data yang tidak sesuai dengan type data. Rencana pengujian field Title data akan valid jika field Title diisi dengan memasukkan angka atau huruf dan tidak boleh kosong. Sebaliknya, data tidak valid jika Title diisi lebih dari 100 Karakter. Pada rencana pengujian Upload Thumbnails data akan valid jika diisi dengan memasukkan gambar ukuran 205x95 pixel dan tidak boleh kosong. Sebaliknya, data tidak valid jika Thumbnails diisi dengan memasukkan memasukan gambar dengan lebih dari 205x95 pixel. Pada rencana pengujian Upload Image data akan valid jika diisi dengan 
memasukkan gambar ukuran 580x225 pixel dan tidak boleh kosong. Sebaliknya, data tidak valid jika Upload Image diisi dengan memasukkan memasukan gambar dengan lebih dari 580x225 pixel.

Tabel 2 Rancangan Test Case Form Data Program/Event

\begin{tabular}{|c|l|l|}
\hline Id & \multicolumn{1}{|c|}{ Deskripsi pengujian } & \multicolumn{1}{c|}{ Hasil yang diharapkan } \\
\hline B01 & $\begin{array}{l}\text { Mengisi Title dengan "Program Pengajian", } \\
\text { Content diisi dengan "Content Pengajian", }\end{array}$ & $\begin{array}{l}\text { Data akan tesimpan ke database dan data yang } \\
\text { Upload Thumbnails diisi dengan "gambar } \\
\text { berukuran 205x95 pixel (*.jpg/png/jpeg)", } \\
\text { Event dan Program Pengajian. } \\
\text { Upload Thumbnails diisi dengan "gambar } \\
\text { berukuran 580x225 pixel (*.jpg/png/jpeg)", } \\
\text { memilih checkbox Tampikan di Home } \\
\text { "Checked" selanjutnya yang harus } \\
\text { dilakukan adalah klik Simpan/Save. }\end{array}$ \\
\hline B02 & $\begin{array}{l}\text { Mengisi Title dengan lebih dari 100 karakter } \\
\text { "abc", Thumbnails diisi dengan images lebih } \\
\text { "205x95 pixel", Thumbnails diisi dengan } \\
\text { images lebih "580x225 pixel" selanjutnya } \\
\text { yang harus dilakukan adalah klik } \\
\text { Simpan/Save. }\end{array}$ & $\begin{array}{l}\text { Menolak untuk tersimpan data tersebut ke dalam } \\
\text { database dan tidak akan muncul di halaman } \\
\text { Program/event pengajian. }\end{array}$ \\
\hline
\end{tabular}

\section{Hasil dan pembahasan}

Pengujian dilakukan pada sistem informasi pengelolaan masjid dengan tujuan untuk mengetahui kekurangan yang ada pada sistem sebelum digunakan oleh pengguna. Hasil dari pengujian jika ditemukan kelemahan dalam sistem maka pengguna bisa mengembangkan pada bagian tersebut yang dianggap lemah. Pada hasil pengujian terdapat tabel test case yang berfungsi untuk menyimpulkan apakah sistem berhasil dalam pengujian atau tidak. Pengujian akan dilakukan dengan metode Black Box berbasis Equivalence Partitions.

Tabel 4 Hasil Pengujian Equivalence Partitions

\begin{tabular}{|c|c|c|c|c|}
\hline Id & Deskripsi Pengujian & Hasil yang diharapkan & Hasil Pengujian & Kesimpulan \\
\hline A01 & $\begin{array}{l}\text { Mengisi E-mail dengan } \\
\text { "rifqiaudi48@gmail.com } \\
\text { dan Password dengan } \\
\text { "admin123" lalu menekan } \\
\text { tombol "Login" }\end{array}$ & $\begin{array}{l}\text { Akses Login berhasil, } \\
\text { system akan } \\
\text { menampilkan form Data }\end{array}$ & $\begin{array}{l}\text { Sistem akan muncul } \\
\text { pesan "berhasil Login" } \\
\text { dan setelah itu sistem } \\
\text { muncul form Data }\end{array}$ & Sesuai \\
\hline A02 & $\begin{array}{l}\text { Mengisi E-mail dengan } \\
\text { "ariefmaulana9898@gmai } \\
\text { 1.com dan Password } \\
\text { dengan "123" lalu } \\
\text { menekan tombol "Login" }\end{array}$ & $\begin{array}{l}\text { Akses Login Gagal, } \\
\text { system tetap } \\
\text { menampilkan form } \\
\text { Login. }\end{array}$ & $\begin{array}{l}\text { Sistem akan muncul } \\
\text { pesan "username atau } \\
\text { password salah" dan } \\
\text { tampilan tetap pada } \\
\text { form Login }\end{array}$ & Sesuai \\
\hline A03 & $\begin{array}{lr}\text { Mengkosongkan } & \text { E-mail } \\
\text { dan Password r lalu } \\
\text { menekan tombol "Login" }\end{array}$ & $\begin{array}{l}\text { Sistem akan menolak } \\
\text { dan menampilkan } \\
\text { "Alamat E-mail dan } \\
\text { Password tidak cocok" }\end{array}$ & $\begin{array}{l}\text { Sistem menampilkan } \\
\text { pemberitahuan } \\
\text { "Alamat E-mail dan } \\
\text { Password tidak cocok" }\end{array}$ & Sesuai \\
\hline & \begin{tabular}{llr} 
Mengisi & Title & dengan \\
"Program & \multicolumn{2}{c}{ Pengajian", } \\
Content & diisi & dengan
\end{tabular} & $\begin{array}{l}\text { Data akan tesimpan ke } \\
\text { database dan data yang }\end{array}$ & $\begin{array}{l}\text { Data behasil tersimpan, } \\
\text { akan muncul pesan }\end{array}$ & Sesuai \\
\hline
\end{tabular}




\begin{tabular}{|c|c|c|c|c|}
\hline B01 & $\begin{array}{lr}\text { "Content } & \text { Pengajian", } \\
\text { Upload Thumbnails diisi } \\
\text { dengan } & \text { "gambar } \\
\text { berukuran } & \text { 205x95 pixel } \\
\text { (*.jpg/png/jpeg)", } & \text { Upload } \\
\text { Thumbnails diisi } & \text { dengan } \\
\text { "gambar } & \text { berukuran } \\
580 x 225 & \text { pixel } \\
(* . j p g / p n g / j p e g) ", & \\
\text { memilih checkbox } \\
\text { Tampikan di Home } \\
\text { "Checked" selanjutnya } \\
\text { yang harus dilakukan } \\
\text { adalah klik Simpan/Save. }\end{array}$ & $\begin{array}{ll}\text { tersimpan } & \text { akan } \\
\text { ditampilkan Pada } & \text { tabel } \\
\text { program/event } & \end{array}$ & $\begin{array}{l}\text { "Data Berhasil } \\
\text { Tersimpan" dan } \\
\text { Data yang tersimpan } \\
\text { ditampilkan di tabel } \\
\text { program/event }\end{array}$ & \\
\hline B02 & $\begin{array}{l}\text { Mengisi Title dengan lebih } \\
\text { dari 100 karakter "abc", } \\
\text { Thumbnails diisi dengan } \\
\text { images lebih "205x95 } \\
\text { pixel", Thumbnails diisi } \\
\text { dengan images lebih } \\
\text { "580x225 pixel" } \\
\text { selanjutnya yang harus } \\
\text { dilakukan adalah klik } \\
\text { Simpan/Save. }\end{array}$ & $\begin{array}{l}\text { Menolak untuk } \\
\text { tersimpan data tersebut } \\
\text { ke dalam database }\end{array}$ & $\begin{array}{l}\text { Data gagal tersimpan } \\
\text { dan menampilkan } \\
\text { pesan kesalahan }\end{array}$ & Sesuai \\
\hline
\end{tabular}

\section{Kesimpulan}

Pemeriksaan yang dilakukan untuk memastikan bahwa fungsi sistem bekerja dengan sebaik-baiknya dan memeriksa kesalahannya. Dalam menentukan tingkat akurasi agar semua parameter akurasi yang terkait seperti tahapan kerahasiaan, integritas data, dan ketersediaan data dapat sesuai dengan kebutuhan, maka diperlukannya proses pengujian metode lain guna sebagai nilai standar keamanan informasi, selain menggunakan metode Equivalence Partitions. Setelah dilakukan pengujian Black Box berbasis Equivalence Partioning terhadap sistem informasi pengelolaan Masjid pada Majelis Taklim Masjid At-Taqwa dapat disimpulkan dalam pengujian tidak ditemukan kesalahan. Penelitian ini telah berhasil merancang bangun Sistem Informasi Kegiatan Masjid di Gunung Sindur Berbasis Web menggunakan Bahasa pemprograman PHP dan database MySQL. Tersedianya prototype tempat berbagi informasi antara para pengurus masjid dengan jamaah masjid atau masyarakat yang ada di sekitarnya dalam bentuk system informasi web. Dengan media Sistem Informasi dan Kegiatan Majelis Taklim At-Taqwa di Gunung Sindur Berbasis Web pengurus dapat mengelola, menginformasikan kegiatan-kegiatan yang dimiliki maupun akan dilaksanakan kepada masyarakat secara lebih luas.

\section{Saran}

Sistem informasi ini dapat dikembangkan lagi dengan menambahkan informasi-informasi lainnya yang relevan terkait aktivitas Masjid AtTaqwa di Gunung Sindur dan juga cakupan lokasinya dapat diperluas untuk berbagai daerah di Indonesia.

\section{Referensi}

Aristoteles, Wardiyanto, \& Pratama, A. A. (2015). Sistem Pakar Diagnosa Penyakit Pada Ikan Budidaya Air Tawar dengan Metode Forward Chaining. Jurnal Komputasi, 3(2), 99-168.

Ferdinandus, S., Wowor, H. F., Lumenta, A. S., \& Rumagit, A. (2012). Perancangan Aplikasi Surat Masuk Dan Surat Keluar Pada PT. PLN (Persero) Wilayah Suluttenggo. Jurnal Teknik Elektro dan Komputer, 1(1), 1-7.

Hidayat, T., \& Muttaqin, M. (2018). Pengujian Sistem Informasi Pendaftaran dan Pembayaran Wisuda Online menggunakan Black Box Testing dengan Metode Equivalence Partitioning dan Boundary Value Analysis. Jutis (Jurnal Teknik Informatika), 6(1), 25-29.

Jaya, M. S., Gumilang, P., Wati, T., Andersen, Y. P., \& Desyani, T. (2019). Pengujian Black Box pada Aplikasi Sistem Penunjang Keputusan Seleksi Calon Pegawai Negeri Sipil Menggunakan 
Teknik Equivalence Partitions. Jurnal Informatika Universitas Pamulang, 4(4), 131136.

Krismadi, A., Lestari, A. F., Pitriyah, A., Mardangga, I. W., Astuti, M., \& Saifudin, A. (2019). Pengujian Black Box berbasis Equivalence Partitions pada Aplikasi Seleksi Promosi Kenaikan Jabatan. Jurnal Teknologi Sistem Informasi dan Aplikasi, 2(4), 155-161.

Latif, A. (2015). Implementasi Kriptografi Menggunakan Metode Advanced Encryption Standar (AES) Untuk Pengamanan Data Teks. Jurnal Ilmiah Mustek Anim, 4(2), 163-172.

Mukhayaroh, A. (2016). Sistem Pendukung Keputusan Pemilihan Distribution Sales Supervisor Dengan Metode FMADM-SAW Pada PT. Nirmala Pangan Sejahtera Bekasi. Informatics for Educators and Professional : Journal of Informatics, 1(1), 51-64.

Mustaqbal, M. S., Firdaus, R. F., \& Rahmadi, H. (2015). Pengujian Aplikasi Menggunakan Black Box Testing Boundary Value Analysis (Studi Kasus : Apilkasi Prediksi Kelulusan SNMPTN). Jurnal Ilmiah Teknologi Informasi Terapan, 1(3), 31-36.

MZ, M. K. (2016). Pengujian Perangkat Lunak Metode Black-Box Berbasis Equivalence Partitions Pada Aplikasi Sistem Informasi Sekolah. Jurnal Mikrotik, 2-8.
Ningrum, F. C., Suherman, D., Aryanti, S., Prasetya, H. A., \& Saifudin, A. (2019). Pengujian Black Box pada Aplikasi Sistem Seleksi Sales Terbaik Menggunakan Teknik Equivalence Partitions. Jurnal Informatika Universitas Pamulang, 4(4), 125-130.

Nurudin, M., Jayanti, W., Saputro, R. D., Saputra, M. P., \& Yulianti, Y. (2019). Pengujian Black Box pada Aplikasi Penjualan Berbasis Web Menggunakan Teknik Boundary Value Analysis. Jurnal Informatika Universitas Pamulang, 4(4), 143-148.

Sasmito, G. W. (2017). Penerapan Metode Waterfall Pada Desain Sistem Informasi Geografis Industri Kabupaten Tegal. Jurnal Pengembangan IT (JPIT), 2(1), 7-12.

Syaban, R. M., \& Bunyamin, H. (2015). Pengembangan Sistem Informasi Pengelolaan Surat Masuk dan Keluar Berbasis Web di Dinas Sosial Tenaga Kerja dan Transmigrasi Kabupaten Garut Menggunakan Framework PHP. Jurnal Algoritma, 12(2), 301-311.

Wahyudi, R., Utami, E., \& Arief, M. R. (2016). Sistem Pakar E-Tourism Pada Dinas Pariwisata D.I.Y Menggunakan Metode Forward Chaining. Jurnal Ilmiah DASI, 17(2), 67-75. 